\title{
Nudging towards tax compliance: A fieldwork- informed randomised controlled trial
}

\author{
Maris Vainre“, Laura Aaben *, Alari Paulus ${ }^{\dagger}$, Helleka Koppel ${ }^{\S}$, Helelyn \\ Tammsaar $^{\S}$, Keiu Telve ${ }^{\S}, K^{\prime}$ atre Koppel ${ }^{\S}, K^{\prime}$ aia Beilmann ${ }^{\S}$, Andero Uusberg
}

\begin{abstract}
Changing complex behaviors such as tax evasion may require several behavioral interventions, or nudges. We developed a tailored compound intervention approach to increase employers' payroll tax compliance in Estonia's construction industry. First, we used anthropological methods to gain insights into the decision processes of employers and employees in the industry (Study 1, $\mathrm{N}=16$ ). These insights were combined with behavioral decision-making principles to design an intervention e-mail with the aim to strengthen perceived risks and weaken descriptive norms of non-compliance as well as to strengthen collaborative and weaken adversarial construal of tax authority. The compound intervention was tested using a three-armed non-blinded randomized controlled trial (Study 2, $\mathrm{N}=4770$ ) involving all employers whose declared wages were below 70\% of the industry's average. The intervention significantly increased declared payroll taxes by $5.1 \%$ to $6.1 \%$ on average across the two treated groups over a 3 -month follow-up period $(\mathrm{p}<.0001)$ and was therefore effective. It remains unclear which constituent nudges of our compound intervention were crucial for this effect. These findings suggest that the compound intervention approach may be a feasible avenue for designing effective interventions in under-studied contexts.
\end{abstract}

Keywords: Payroll taxes, Compliance, Field experiment, Behavioral insights, Nudges

Supplements: $\underline{\text { Open materials }}$

$\mathrm{E}$ ffective tax collection is key to a well-functioning state. Tax evasion is thus a major policy concern in much of the OECD. In Estonia, the government is estimated to have missed out on $4.9 \%$ of its budget or $1.44 \%$ of GDP due to the shadow economy (Maksu- ja Tolliamet, 2017). One promising approach to combating tax evasion involves applying nudges, or small interventions designed to leverage insights about how people behave (for an overview, see Blackwell, 2007; Hallsworth, 2014; Hallsworth,

\footnotetext{
* Praxis Centre for Policy Studies

† Institute for Social and Economic Research (ISER), University of Essex / Praxis Centre for Policy Studies

$\int$ Center for Applied Anthropology of Estonia

$\perp$ University of Tartu

Address correspondence to Maris Vainre at (maris@praxis.ee)

Copyright: C 2019. The authors license this article under the terms of the Creative Commons Attribution 4.0 International License.
}

List, Metcalfe, \& Vlaev, 2017). This approach, however, has yielded mixed results.

Most field experiments employing nudges towards tax compliance have tested the effects of nudges using either a non-deterrence or a deterrence framework. Non-deterrence nudges have targeted social norms (Blumenthal \& Christian, 2001; Castro \& Scartascini, 2015; Fellner, Sausgruber, \& Traxler, 2013; Hallsworth et al., 2017; Hasseldine, Hite, James, \& Toumi, 2007; John \& Blume, 2018), moral persuasion (Ariel, 2012; Fellner, Sausgruber, \& Traxler, 2013; Hasseldine et al., 2007; Torgler, 2004; Wenzel, 2006), and reciprocity (Blumenthal \& Christian, 2001; Castro \& Scartascini, 2015; Hallsworth, et al., 2017; Hasseldine et al., 2007). Deterrence nudges have targeted awareness of legal sanctions (Hasseldine et al., 2007; Iyer, Reckers, \& Sanders, 2010; Schwartz \& Orleans, 1967), and the perceived risk of getting caught or being audited (Ariel, 2012; Fellner et al., 2013; Gangl, Torgler, Kirchler, \& Hofmann, 
2014; Hasseldine etal., 2007; Iyer, et al., 2010; Kleven, Knudsen, Kreiner, Pedersen, \& Saez, 2011; Pomeranz, Alesina, Asher, Casaburi, Chetty, Cutler, Weinzierl, 2013; Schwartz \& Orleans, 1967). While some of these studies have demonstrated significant improvements in tax compliance, others have not (Hallsworth, 2014) or have found an intervention to backfire by reducing tax compliance (Ariel, 2012; Gangl et al., 2014; Mendoza, Wielhouwer, \& Kirchler, 2017). Therefore, policy-makers may find it difficult to design evidence-informed interventions that would increase the likelihood of tax compliance.

One reason for mixed results in previous trials may be their relatively narrow focus on targeting a single underlying psychological mechanism at a time. While such focus makes it easier to infer causes of observed effects, it may not be optimal for maximising intervention effectiveness. Each individual psychological mechanism tends to have only a small and context-dependent effect on a complex behavioural pattern such as tax compliance (Funder \& Ozer, 2019). Meanwhile, there could be further interactions between different nudges, so that a combination of them enhances (or offsets) their individual effects. The existing evidence describing the effects of single nudges is therefore insufficient for designing interventions that seek to amplify effectiveness by combining several nudges. In addition, policy-makers need a systematic way to combine different nudges into context-sensitive effective interventions. To this end, we propose a tailored compound intervention (TCI) approach which involves combining several nudges based on an analysis of the relevant complex behaviour.

Akin to a personalised combination of medications, TCIs facilitate behavioral change by combining several active ingredients (i.e., nudges) to simultaneously target several mechanisms underlying one problematic behavior (i.e., tax evasion). Designing tailored compound interventions involves two steps. First, a working model needs to be constructed that identifies potential intervention targets among the decisions that the target group makes, consciously or otherwise, when engaging in the problematic behaviour. Second, a compound intervention needs to be designed by selecting which of the identified targets can be addressed with a feasible combination of available nudges. This approach does not guarantee finding the most efficient combination of "active ingredients". However, for complex behaviors and in circumstances where there is little evidence of the effectiveness of individual nudges, a theory-based TCI is a useful starting point for creating evidence-based interventions.

In the present article, we assess the feasibility of the TCI approach by applying it to increase payroll tax compliance in the construction sector in Estonia. Payroll taxes - here considered in a broad sense, covering all labor taxes and contributions either payed by the employer or withheld on behalf of the employee - are a complex and understudied aspect of tax compliance. Evidence from prior field experiments targeting the behavior of individual taxpayers may not generalise to the behavior of employers and companies (see Hallsworth, 2014). At present, it is unclear whether nudges can affect employers' tax behavior - out of five studies reported by Hallsworth (2014), only two reported significant positive effects (Ortega \& Sanguitti, 2013; Pomeranz et al., 2013).

In this paper, we will focus on payroll tax compliance in the construction industry which has been among the top shadow economy concern areas for tax authorities (OECD, 2012). To apply the TCI approach for reducing payroll tax evasion, we first developed a working model of payroll tax compliance in the construction industry by combining existing literature with an anthropological study of the target group, summarised as Study 1 in this paper. We then designed a compound intervention and conducted a randomised controlled trial to assess its effectiveness, presented as Study 2 in this paper.

\section{Study 1: Identifying Intervention Targets}

To establish a working model of the decision-making processes governing employer's compliance with payroll taxes in Estonia, we combined insights from the psychology of tax compliance (Kastlunger, Lozza, Kirchler, \& Schabmann, 2013; Kirchler, Muelbacher, Kastlunger, \& Wahl, 2010) with an empirical study of representatives of the industry.

\section{Method}

Fifteen semi-structured in-depth interviews with 16 interviewees were conducted in January and February 2018. The volunteer sample was a cross-section of the population in terms of gender, age, tenure, size of company, status, and mother tongue (for more detail, please see Appendix A). The interviews were recorded and transcribed by the interviewers, with the assurance that the interviewees would remain anonymous to the remaining research group as well as representatives of the Estonian Tax and Customs Board 
(TCB). The transcripts were analysed to identify major narrative themes (Braun \& Clarke, 2006) characterising the target group's decision-making (see Appendix $C$ for details). The analysis was conducted by the corresponding author, triangulating the results with other co-authors, including the interviewers. The emerging themes were also situated within psychological models of tax compliance and nudge interventions, yielding a working model of the tax compliance decision.

\section{Results}

Four major themes emerged from the interviews.

Not paying pays off. The employers characterised tax compliance in terms of a cost-benefit analysis. In order to survive the competitive market, especially that of sub-contracts, employers felt forced to take up projects that have low to no profit margins. Within this framework, evading taxes became a way to "save" money so long as the risk of getting caught was considered low.

Not paying is the norm. We found the subcontractors deemed undeclared salaries the norm: "I don't know any company where the whole salary is paid officially" (Interviewee 5). A few respondents also thought that the shadow economy was in decline.

Unfair government. Several interviewees found the government overly controlling of the entrepreneurs while allowing politicians to spend irrat- ionally. Others had either had a negative experience with a government agency (e.g., TCB or the police) or did not think they were receiving enough public services in return (e.g., long healthcare waiting lists). This led to a sense of unfairness: paying tax was seen as handing out money in order to employ "an army of bureaucrats" with no reciprocated benefit.

Red tape. Several employers suggested that considering the burdening amount of bureaucracy, some agreements and financial deals were easier done "unofficially": "Generally, there's the understanding in the construction industry that since the tax system is so complicated, it's better to avoid it altogether." 1 (Interviewee 10).

\section{Discussion}

The qualitative analysis suggested that low tax compliance in the construction industry is facilitated by the hierarchical and asymmetrical power structures between the main contractors and subcontracts that undermine fair competition, and a strong sense of disappointment in the government and the public sector. Combining these themes with principles of tax compliance psychology yielded a working model of the target group's decisions processes regarding tax evasion, summarised in Table 1.

The model firstidentifies four broad sets of features that influence decisions to pay payroll taxes in the Estonian construction sector: expected outcomes,

Table 1

Working Model of Potential Intervention Targets among Decision Processes Involved in Payroll Tax Compliance in the Estonian Construction Industry

\begin{tabular}{lll}
\hline \hline Feature set & Prevention target & Promotion target \\
\hline Expected outcomes & $\begin{array}{l}\text { Weaken perceived benefit } \\
\text { "No need to save on taxes to } \\
\text { be competitive" } \\
\text { Weaken descriptive norm } \\
\text { "Most of my peers pay taxes" }\end{array}$ & $\begin{array}{l}\text { Strengthen perceived risk } \\
\text { "I might get caught and be } \\
\text { fined" }\end{array}$ \\
$\begin{array}{ll}\text { Wentrengthen injunctive norm } \\
\text { "The best employers pay taxes" }\end{array}$ \\
Construal of tax authority adversarial con- & $\begin{array}{l}\text { Strengthen collaborative con- } \\
\text { strual of tax authority }\end{array}$ \\
& $\begin{array}{l}\text { "The government is not unfair } \\
\text { and wasteful" }\end{array}$ & $\begin{array}{l}\text { "My taxes are important invest- } \\
\text { ments into Estonia" }\end{array}$ \\
Tax procedures & $\begin{array}{l}\text { Reduce perceived effort } \\
\text { "Paying taxes is frictionless" }\end{array}$ & $\begin{array}{l}\text { Improve perceived ease } \\
\text { "Paying taxes is easy" }\end{array}$ \\
\hline $\begin{array}{l}\text { Notes. Each target is illustrated by a hypothetical expression of a target group member induced by an intervention; } \\
\text { targets marked in bold were selected for targeting by the compound intervention tested in Study 2. }\end{array}$
\end{tabular}


identity, construal of tax authority, and tax procedures. It then identifies potential targets for intervention among each of the identified four decision features. It further distinguishes between prevention targets-decision processes that have an undesirable impact on tax compliance and should therefore be prevented by an intervention, and promotion targets-decision processes that have a desirable impact on decisions and should therefore be promoted by an intervention.

\section{Study 2: Nudging Construction Industry towards Payroll Tax Compliance}

We selected four intervention targets out of the eight described in Table 1 for the TCI tested in Study 2. The selection was based on expert judgements of the authors, relying on existing evidence of nudging effectiveness as well as evidence collected in Study 1. More specifically, we evaluated each element in the model presented in Table 1 using three criteria: a) to what extent would a change in the given decision feature lead to a change in tax compliance, b) to what extent could the given decision feature be changed via e-mail and text messaging, and c) what is the risk that a nudge targeting this element would backfire?

Four potential intervention targets had favourable assessments on all three criteria: 1) strengthening perceived risk; 2) weakening descriptive norms; 3) weakening adversarial construal of tax authority, and 4) strengthening collaborative construal of tax authority. Strengthening perceived risk of audit has been reported to increase tax compliance between 2 and 14.1 percentage points (DelCarpio, 2014; Fellner, Sausgruber, \& Traxler, 2013; Hasseldine, Hite, James, \& Toumi, 2007; Pomeranz, Alesina, Asher, Casaburi, Chetty, Cutler, Weinzierl, 2013). Similarly, descriptive norms have been suggested to improve compliance by 1.3 to 5.1 percentage points (Del Carpio, 2014; Hallsworth, List, Metcalfe, \& Vlaev, 2017; Hasseldine, Hite, James, \& Toumi, 2007). Finally, altering the construal of tax authority has been recommended on conceptual grounds (Kirchler, Hoelzl, \& Wahl, 2008), although more empirical evidence is needed to estimate its effectiveness. We decided to include it since the theme strongly emerged from the data collected in Study 1.

The four remaining potential targets, by contrast, were deemed not to meet one or more of the criteria. We decided against weakening perceived benefits as we could not change the conditions in the industry that give rise to this perception. We decided against strengthening injunctive norms to avoid the risk of backfiring. Tax compliance is more common among larger companies and less common among smaller companies that depend on the larger ones for revenue. Therefore, a message highlighting the larger companies as role models may further aggravate the sense of injustice felt by the smaller companies. Finally, we also decided against reducing perceived effort or improving perceived ease of tax compliance given that these decision features were deemed not to have a sufficiently large effect on payroll tax compliance behaviour.

\section{Method}

\section{Intervention}

In collaboration with both the TCB and the interviewers, we designed two versions of an e-mail which included several manipulations addressing the four targets identified in Table 1. We chose e-mails as our medium since it is used in most communication between government agencies and citizens in Estonia while paper letters are rare. The two e-mail versions differed in the description of potential penalties, which was implicit in one and explicit in the other (see Appendix D for the translation of the e-mails together with the intervention targets). The primary target was to strengthen perceived risks: the e-mail announced new initiatives including upcoming audits to combat undeclared payroll taxes (though not strictly related to the intervention), suggested that the recipient may be selected for the audit, and implied the audit may be avoided through increased compliance. To further bolster a sense of accountability, the e-mails were addressed to the board of management, greeted them by their full names, and used the company name in the body of the e-mail.

Additionally, the letters weakened the adversarial construal of the tax authority by stating that assuring fair competition is a priority for the TCB - a common concern for the entrepreneurs as well as the TCB. Furthermore, the letters strengthened the collaborative construal of the tax authority by exemplifying the investment value of payed payroll taxes. The letters stated that the overall lost revenue is about the same as the combined annual budgets of ambulance and fire services - two services that have enjoyed the highest levels of public trust in Estonia (Kivirähk, 2018). Fourth, the letters weakened descriptive norms by stating that $92 \%$ of employees receive their salaries with due taxes deducted. ${ }^{2}$ All the facts in the letters were accurate and reflected our be- 
st knowledge.

\section{Participants}

The sample included employers in the construction industry according to the Estonian Classification of Economic Activities' code. Eligibility criteria were assessed by an analyst in the TCB. We included employers who, in the period of October 2017 to March 2018, had declared payments to their employees that were lower than $70 \%$ of the average in the construction industry over the same time period. This criterion is used by TCB to calculate their risk factor for tax evasion. We excluded employers who, at the time of calculating the $70 \%$ cut-off, were audited by TCB. Among the remaining pool of employers, intervention groups' chances of being audited were the same as for the control group. Companies that met the eligibility criteria were pseudonymised at the TCB and sent to the corresponding author. See Figure 1 for details.

\section{Procedures}

E-mails were sent to two intervention groups. The control group did not receive an e-mail, and thus is considered as the business as usual (BAU) group. To heighten the chances of the e-mail being read, we also sent all its recipients the following mobile text message: "The Tax and Customs Board has sent you a message to [email address]". We were not able to determine whether the recipients read the text messages or the e-mails.

Both the e-mails and the text messages were sent using TCB's in-house software, IRIS, on 29th May 2018. Because of the legal requirement to use IRIS which does not allow randomisation within its system, we could not run a blinded trial. Instead, the TCB provided us with a pseudonymised list of employers, which we randomly allocated to the two intervention groups and the BAU group. The randomisation of the employers (1:1:1) was done by the corresponding author using RStudio version 1.0.136 running on $\mathrm{R}$ version $\mathrm{x} 64$ 3.3.1 and the package randomize R (Uschner, Schindler, Hilgers, \& Heussen, 2018).

An information phone line was set up by the TCB with a number provided in the e-mails. The call centre personnel were aware of the trial but unaware of its contents and blinded to the randomisation. They were instructed to consult the clients as usual, without revealing the experiment, to avoid affecting recipients' behavior. To test the impact of the e-mails on TCB's customer services, we ran a pilot study with
150 employers (randomised 1:1:1, more details in Appendix E). The participants of the pilot study were excluded from the main study and their data are not included in the analyses reported in this paper.

\section{Measures}

The effect of the interventions was measured using data from TCB's routine employers' monthly payroll tax declarations. We observed declared employer social insurance contributions (social tax) as well as employee social insurance contributions (unemployment, funded pension) and personal income tax with held from gross salaries by employers - here labelled altogether as 'payroll taxes' - adjusted for the number of full time equivalent (FTE) employees. Payroll taxes declared for the month of April and May, that is prior to the intervention, were considered as the baseline. We investigated the effect of the intervention on payroll taxes declared for June, July, and August. The TCB provided information on the following variables: number of employees, full-time equivalent (FTE) employees, declared gross salary, social tax, unemployment insurance contribution, funded pension contribution, and personal income tax.

\section{Statistical Analyses}

Our main dependent variable is the amount of payroll taxes, adjusted for the number of full-time equivalent workers, though we also ran alternative models for (log) gross earnings (FTE) and obtained qualitatively similar results (available on request). To estimate the treatment effects on payroll taxes per FTE, we used the difference-in-difference approach with employer-level monthly panel data. The regression model includes time and group fixed effects and the interaction terms between the groups and the intervention (either implicit (I) or explicit (E) outcomes condition):

$$
y_{i g t}=\gamma_{g}+\lambda_{t}+\beta_{g} I_{g t}+\varepsilon_{i g t}
$$

where $y_{i g t}$ is the dependent variable reported by firm $i(i=1 \ldots N)$ in group $g$ (BAU, implicit outcomes, explicit outcomes) for month $t(t=A p r, \ldots, A u g), \gamma_{g}$ is the group fixed effect), $\lambda_{t}$ captures the time trend (i.e. dummies for months), $I_{g t}$ is a dummy denoting whether group $g$ has been exposed to the intervention by time $t$, (e-mails were sent out in May, after tax declaration), and $\varepsilon_{i g t}$ is an error term. We sought to estimate the values of $\beta_{g}$, i.e. coefficients for firms receiving either the implicit or explicit outcomes e- 


\section{Figure 1 \\ Study Profile. Consort 2010 Flowchart.}

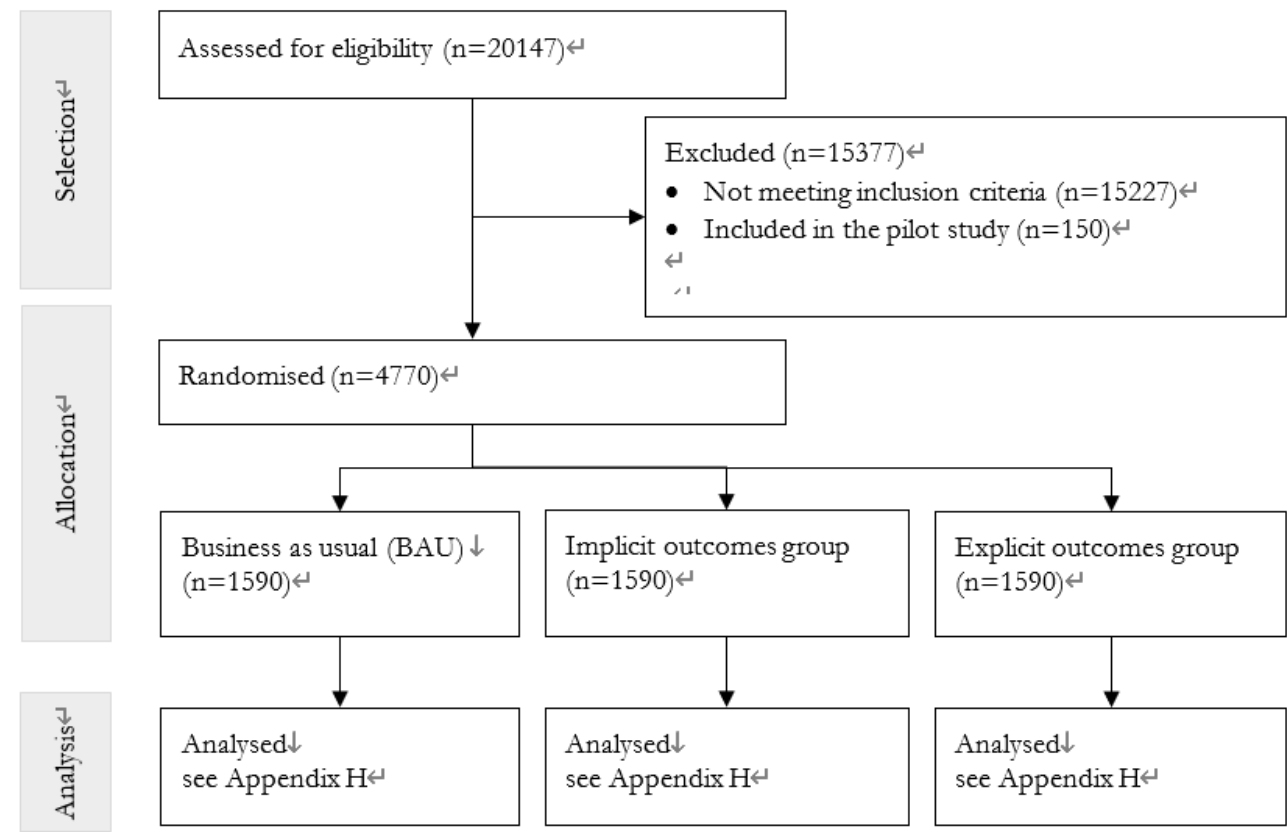

mail relative to BAU while controlling for the overall time trend.

\section{Role of the Funding Source}

While we did cooperate with the funders when designing the study - to ensure its feasibility and applicability considering the TCB standard operating procedures - the funders had no role in the data analysis, data interpretation, or write-up of this paper. The corresponding author had full access to the pseudonymised raw data and made the final decision to submit for publication.

\section{Results}

We first confirmed that the randomisation procedure had indeed produced comparable groups-the employers included in different arms of the study were similar in terms of number of employees and FTEs (Appendix F).

Next, we estimated the linear panel data model of tax payments both with the fixed-effects (FE) and random-effects $(\mathrm{RE})$ estimator. Both models were statistically highly significant: F statistic 103.08 for the FE model $(\mathrm{p}<0.001)$ and Wald chi2 statistic 630.22 for the RE model $(\mathrm{p}<0.001)$. Here we present the latter as the Hausman test could not reject the null hypothesis that the RE estimator provides consistent estimates $(p=0.26)$. The results with the FE estimator are shown in Appendix $\mathrm{H}$.

The results of the regression analysis (Table 2) reveal, first of all, the lack of statistically significant differences between the intercept for the BAU group and the implicit outcomes treatment group $\left(\gamma_{I}=\right.$ $4.09, p=0.42)$ and the explicit outcomes group $\left(\gamma_{E}=7.18, p<0.16\right)$. This finding further confirms that the three arms of the study did not differ in their baseline tax reporting. Second, there was a clear time trend with the average amount of payroll taxes increasing from $€ 15.54$ (May) to $€ 32.00$ (August).

Finally, and most importantly, we found a positive and highly statistically significant effect for both e-mails $\left(\gamma_{I}=11.95, p=.0001 ; \gamma_{E}=15.38, p<\right.$ $.0001)$. This amounts to an increase of $5.1 \%$ and $6.1 \%$, respectively, compared to the average payroll taxes in the BAU group at the start of period $(€ 233.30$, see Appendix G). Although the effect is larger for the explicit outcomes e-mail, the difference between the two groups is not statistically significant based on the Wald test $(p=0.26)$.

To investigate the treatment effects month-bymonth, we also estimate another version of the 
Table 2

Estimation Results for Random-Effects Panel Model

\begin{tabular}{|c|c|c|c|c|c|c|c|}
\hline & & \multirow[b]{2}{*}{ Coef. } & \multirow[b]{2}{*}{ SE } & \multirow[b]{2}{*}{$\mathbf{z}$} & \multirow[b]{2}{*}{$p$} & \multicolumn{2}{|c|}{ 95\% CI } \\
\hline & & & & & & Lower & Upper \\
\hline \multicolumn{2}{|l|}{ Intercept } & 231.08 & 3.74 & 61.87 & $<0.0001$ & 223.76 & 238.40 \\
\hline \multicolumn{2}{|c|}{ Implicit outcomes group } & 4.09 & 5.09 & 0.80 & 0.42 & -5.89 & 14.07 \\
\hline \multicolumn{2}{|c|}{ Explicit outcomes group } & 7.18 & 5.11 & 1.40 & 0.16 & -2.84 & 17.21 \\
\hline \multirow[t]{2}{*}{ Pre-intervention } & April-May & 15.54 & 1.91 & 8.15 & $<0.0001$ & 11.81 & 19.28 \\
\hline & June & 21.50 & 2.62 & 8.21 & $<0.0001$ & 16.37 & 26.63 \\
\hline \multirow[t]{2}{*}{ Post-intervention } & July & 26.28 & 2.61 & 10.05 & $<0.0001$ & 21.15 & 31.40 \\
\hline & August & 32.00 & 2.63 & 12.19 & $<0.0001$ & 26.86 & 37.15 \\
\hline \multirow{2}{*}{\multicolumn{2}{|c|}{$\begin{array}{l}\text { Implicit outcomes group inter- } \\
\text { acted with the treatment } \\
\text { Explicit outcomes group inter- } \\
\text { acted with the treatment }\end{array}$}} & 11.95 & 3.06 & 3.91 & $<0.0001$ & 5.95 & 17.94 \\
\hline & & 15.38 & 3.06 & 5.02 & $<0.0001$ & 9.37 & 21.38 \\
\hline
\end{tabular}

Figure 2

Regression Estimates for the Treatment Groups in Comparison to the Control Group over Time (Differences-in-Differences)

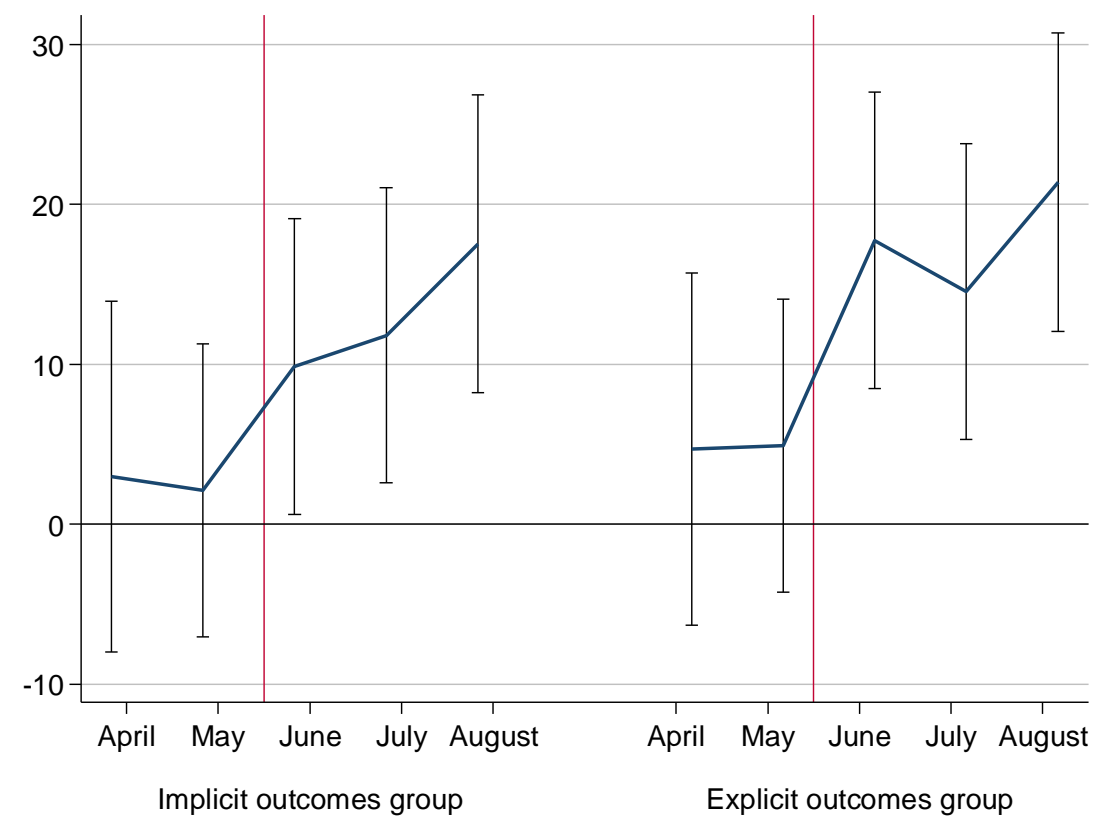

Notes: Vertical lines indicate when the intervention took place; 95\% CI shown.

model interacting every month with the treatment groups $\left(D_{g t}\right)$ :

$$
y_{i g t}=\gamma_{g}+\lambda_{t}+\beta_{g t} D_{g t}+\varepsilon_{i g t}
$$

Figure 2 presents the results and demonstrates how statistically significant differences between the BAU and either treatment group emerged after the intervention. The effect was immediate with the explicit 
outcomes e-mail but more gradual with the implicit outcomes e-mail. Month-by-month estimates also suggest that the implicit outcomes group was slower to raise their payroll tax declarations compared to the explicit outcomes group, though the difference is not statistically significant as demonstrated by overlapping confidence intervals.

\section{Discussion}

Our findings suggest that the tailored compound intervention e-mails increased the amount of payroll tax declared by the employers compared to the condition where no communication was received from the tax authority. The letters significantly ( $\mathrm{p} \leq .0001$ ) improved tax declarations per FTE employee, on average by $5.1-6.1 \%$ across the two intervention groups compared to not receiving an e-mail (BAU). This effect is comparable to the results reported in previous studies. Additionally, we found that the implicit outcomes group was slower to raise the amounts declared as payroll taxes compared to the explicit outcomes group, though the differences were not statistically significant. It is also worth emphasising that our sample constituted population data for the target group (i.e. all construction firms reporting taxes below a certain level), meaning there was no uncertainty left in the statistical sense. Still, we have taken a conservative approach and treated the data as a random sample of an infinite population and correspondingly calculated standard errors for our estimates.

\section{Conclusion}

In search of effective ways to apply behavioral insights to improve tax compliance, we proposed a tailored compound intervention approach and assessed its feasibility in improving payroll tax reporting in the Estonian construction industry. We developed a working model of the problematic behavior, integrating known psychological principles with qualitative evidence of the target group. We identified eight conceivable intervention targets of which we selected four for our intervention based on expertassessments of their likely malleability to nudges, feasibility for nudging through e-mail, and low likelihood of backfire. We tested the effectiveness of the designed intervention using a three-armed randomised control trial. We found the intervention effective, improving tax revenues per FTE employee by 5.1-6.1 percent over a 3 -month period $(p \leq .0001)$.
We also compared the effect of implicit and explicit descriptions of possible outcomes of TCB discovering a tax fraud. While Wenzel and Taylor (2004) found that their harder-toned letter led to significantly lower overall deduction claims than a softer letter, our results suggest that over a 3-month period, both approaches yielded similar results. Based on this finding, we propose that implicit threats of consequences may offer a useful balance between increasing tax compliance and maintaining favorable public perception of the tax authority (see also Alm \& Torgler, 2011).

One of the nudges included in our intervention — that of altering the construal of tax authority has thus far not been widely reported. Meanwhile a similar concept, moral persuasion, has been reported to have a backfiring effect (Torgler, 2004, Pomeranz et al 2013). Although we cannot estimate the effect of any particular constituent nudge within our compound intervention, contrasting the past backfiring effect with the present findings suggests that moral arguments may have a more favorable effect when they are not the dominant message, but instead are somewhat concealed within a broader message. This hypothesis could be worth investigating in future studies, especially in populations that convey adverse opinions towards the tax authority.

Our study focused on employers in the construction industry whose low declared salary (below $70 \%$ of the market average) indicated a risk for tax evasion. The present findings cannot therefore be generalised with certainty to more compliantemployers in the same industry. Both larger and smaller effects are conceivable. On the one hand, our TCI might have an even larger effect on more compliant employers, if they are more sensitive to a nudge than the less compliantemployers. On the other hand, our TCI might also have a smaller effect on more compliant employers due to regression to the mean-employers who already pay salaries closer to the market average may be less responsive to such an intervention.

One inevitable limitation of the targeted compound intervention approach employed in this study is that it does not enable us to infer the effectiveness of each individual constituent nudge. Without future studies, we cannot conclude which proportions of the effects we observed can be attributed to strengthening perceived risk, weakening descriptive norms, or weakening adversarial and strengthening collabo- 
rative construal of tax authority. We also cannot establish that our combination of nudges was necessarily the best among all possible combinations. However, it is unlikely that researchers will ever be able to measure the effectiveness of all feasible combinations of different nudges targeting different behaviors of different target groups in different contexts. Policy-makes therefore need an alternative way to design effective interventions that would leverage existing evidence about what is known to work as well as context-specific knowledge of the target group and its circumstance. We hope that the fieldwork-informed tailored compound intervention approach presented here can serve as a roadmap to build evidencein under-researched areas. To this end, the present study demonstrates several advantages of this approach. The study was conducted in a distinct context-employers' tax compliance in a specific country-for which very little evidence exists as to which psychological factors underly the unwanted behaviours and which nudges would be effective in changing these factors. It was also not practically feasible to devise a large number of interventions testing various nudges separately, given the relatively small size of the target population. The TCI approach was helpful in this context, by providing a flexible way to construct a working model of the underlying behavior and supporting informed design of a compound intervention.

\section{Acknowledgements}

The development of the intervention and its testing was funded by TCB. The write-up was part-funded by Praxis Centre for Policy Studies and the Estonian Research Council grant MOBTP-17. The views ex- pressed are those of the authors and do not necessarily represent those of the TCB nor Praxis. We would like to thank Oscar Õun, Raul Jõgi, Imbi Kaunismaa, and Rainer Laurits for their cooperation and insights throughout the project and Jane Ester and Kerttu Sobak for their contributions to this project. Many thanks to the interviewees as well as to the participants of the workshop intended to synthesise interview data with behavioral insights in order to develop the intervention. MV would also like to express her gratitude to Dr Julieta Galante for her consultations in the preparation phase of the RCT and for her overall moral support in the later stages of this project. Please also note, that MV has recently started her PhD studies at the MRC Cognition and Brain Sciences Unit at the University of Cambridge and can thus also be reached at Maris.Vainre@mrccbu.cam.ac.uk.

\section{Supplementary Materials}

All Appendixes can be found in the online supplementary materials at http://journal-bpa.org/index.php/ibpa/article/view/84

\section{Notes}

1. There was a personal income tax reform, which took effect from 1 January 2018. While before the reform, income tax was paid largely proportionally to one's gross income, the reform introduced a gradient whereby those earning less paid a smaller proportion.

2. This was, at the time, our best knowledge, based on Josing (2017).

\section{References}

Alm, J., \& Torgler, B. (2011). Do ethics matter? Tax compliance and morality. Journal of Business Ethics, 101, 635-651. https://doi.org/10.1007/s10551-011-0761-9

Ariel, B. (2012). Deterrence and moral persuasion effects on corporate tax compliance: Findings from a randomized controlled trial. Criminology, 50, 2769.

https:/ / doi.org/10.1111/j.17459125.2011.00256 .x

Blackwell, C. (2007). A meta-analysis of tax compliance experiments. Annual Meeting of the Public Choice Society and Economic Science Association, 21. https:/ / doi.org/10.4324/9780203851616

Blumenthal, M., \& Christian, C. (2001). Compliance? Evidence from a controlled experiment in Minnesota. National Tax Journal, 54, 125-138.

Braun, V., \& Clarke, V. (2006). Using thematic analysis in psychology. Qualitative Research in Psychology, 3, 77-101. https://doi.org/10.1191/1478088706qp063oa

Castro, L., \& Scartascini, C. (2015). Tax compliance and enforcement in the pampas evidence from a field experiment. Journal of Economic Behavior and Organization, 116, 65-82.

https://doi.org/10.1016/j.jebo.2015.04.002 
Del Carpio, L. (2014). Are the neighbors cheating? Evidence from a social norm experiment on property taxes in Peru. Unpublished Manuscript.

Fellner, G., Sausgruber, R., \& Traxler, C. (2013). Testing enforcement strategies in the field: Threat, moral appeal and social information. Journal of the European Economic Association, 11, 634-660. https://doi.org/10.1111/jeea.12013

Funder, D. C., \& Ozer, D. J. (2019). Evaluating effect size in psychological research: Sense and nonsense. Advances in Methods and Practices in Psychological Science, 2515245919847202. https://doi.org/10.1177/2515245919847202

Gangl, K., Torgler, B., Kirchler, E., \& Hofmann, E. (2014). Effects of supervision on tax compliance: Evidence from a field experiment in Austria. Economics Letters, 123, 378-382. https:// doi.org/10.1016/j.econlet.2014.03.027

Hallsworth, M. (2014). The use of field experiments to increase tax compliance. Oxford Review of Economic Policy, 30, 658-679. https://doi.org/10.1093/oxrep/gru034

Hallsworth, M., List, J. A., Metcalfe, R. D., \& Vlaev, I. (2017). The behavioralist as tax collector: Using natural field experiments to enhance tax compliance. Journal of Public Economics, 148, 14-31. https:// doi.org/10.1016/j.jpubeco.2017.02.003

Hasseldine, J., Hite, P., James, S., \& Toumi, M. (2007). Persuasive communications: Tax compliance enforcement strategies for sole proprietors. Contemporary Accounting Research, 24, 171-194. https:/ / doi.org/10.1506/P207-004L-42057NX0

Iyer, G. S., Reckers, P. M. J., \& Sanders, D. L. (2010). Increasing tax compliance in Washington state: A field experiment. National Tax Journal, 63, 7-32. https://doi.org/10.17310/ntj.2010.1.01

John, P., \& Blume, T. (2018). How best to nudge taxpayers? The impact of message simplification and descriptive social norms on payment rates in a central London local authority. Journal of Behavioral Public Administration, 1. https://doi.org/10.30636/jbpa.11.10

Josing, M. (2017). Varimajanduse trendid. [Trends in the shadow economy]. Tallinn, Estonia.

Kastlunger, B., Lozza, E., Kirchler, E., \& Schabmann, A. (2013). Powerful authorities and trusting citize-ns: The slippery slope framework and tax complia-

nce in Italy. Journal of Economic Psychology, 34, 3645. https://doi.org/10.1016/j.joep.2012.11.007

Kirchler, E., Hoelzl, E., \& Wahl, I. (2008). Enforced versus voluntary tax compliance: The "slippery slope" framework. Journal of Economic Psychology, 29, 210-225.

https:// doi.org/10.1016/j.joep.2007.05.004
Kirchler, E., Muelbacher, S., Kastlunger, B., \& Wahl, I. (2010). Why pay taxes? A review of tax compliance

decisions. In J. Alm, J. Martinez-Vazquez, \& B. Torgler (Eds.), Developing Alternative Frameworks for Explaining Tax Compliance (Vol. 9780203851, pp. 15-31). Oxon, UK: Routledge. https://doi.org/10.4324/9780203851616

Kivirähk, J. (2018). Avalik arvamus ja rïgikaitse [Public opinion and national defense]. Tallinn, Estonia.

Kleven, H. J., Knudsen, M. B., Kreiner, C. T., Pedersen, S., \& Saez, E. (2011). Unwilling or unable to cheat? Evidence from a tax audit experiment in Denmark. Econometrica, 79, 651-692. https://doi.org/10.3982/ECTA9113

Maksu- ja Tolliamet. (2017). Kokkuvõte 2017. aastast [Summary of 2017]. Tallinn, Estonia.

Mendoza, J. P., Wielhouwer, J. L., \& Kirchler, E. (2017). The backfiring effect of auditing on tax compliance. Journal of Economic Psychology, 62, 284 294. https://doi.org/10.1016/j.joep.2017.07.007

OECD. (2012). Reducing opportunities for tax noncompliance in the underground economy.

Ortega, D. E., \& Sanguitti, P. (2013). Deterrence and reciprocity effects on tax compliance: Experimental evidence from Venezuela (No. 2013/08). CAF Working Papers.

Pomeranz, D., Alesina, I. A., Asher, S., Casaburi, L., Chetty, R., Cutler, D., ... Weinzierl, M. (2013). No Taxation without Information: Deterrence and SelfEnforcement in the Value Added Tax (NBER Working Paper Series No. 19199). Cambridge, MA.

Schwartz, R. D., \& Orleans, S. (1967). On legal sanctions. The University of Chicago Law Review, 34, 274 300. https://doi.org/10.2307/1598934

Torgler, B. (2004). Moral suasion: An alternative tax policy strategy? Evidence from a controlled field experiment in Switzerland. Economics of Governance, 5, 235-253. https://doi.org/10.1007/s10101-004-0077-7

Uschner, D., Schindler, D., Hilgers, R.-D., \& Heussen, N. (2018). randomizeR: An R package for the assessment and implementation of randomization in clinical trials. Journal of Statistical Software, 85, 122.

https://doi.org/10.18637/jss.v085.i08

Wenzel, M. (2006). A letter from the tax office: Compliance effects of informational and interpersonal justice. Social Justice Research, 19, 345-364. https://doi.org/10.1007/s11211-006-0011-y

Wenzel, M., \& Taylor, N. (2004). An experimental evaluation of tax-reporting schedules: A case of evidence-based tax administration. Journal of Public Economics, 88, 2785-2799.

https://doi.org/10.1016/j.jpubeco.2003.10.001 